OPEN ACCESS

Edited by: Alma Balestrazzi,

University of Pavia, Italy

Reviewed by:

Abdelali Hannoufa,

Agriculture and Agri-Food Canada

(AAFC), Canada

Qian Shen,

Shanghai Jiao Tong University, China

*Correspondence:

Calum Watt

calumwatt12@outlook.com

Specialty section:

This article was submitted to Plant Metabolism and Chemodiversity,

a section of the journal

Frontiers in Plant Science

Received: 10 June 2020 Accepted: 05 August 2020

Published: 18 August 2020

Citation:

Watt C, Zhou G and Li C (2020) Harnessing Transcription Factors as Potential Tools to Enhance Grain Size Under Stressful Abiotic Conditions in

Cereal Crops.

Front. Plant Sci. 11:1273.

doi: 10.3389/fp/s.2020.01273

\section{Harnessing Transcription Factors as Potential Tools to Enhance Grain Size Under Stressful Abiotic Conditions in Cereal Crops}

\author{
Calum Watt ${ }^{*}$, Gaofeng Zhou and Chengdao Li \\ Western Crop Genetics Alliance, Murdoch University, Perth, WA, Australia
}

Predicted climate change is widely cited to significantly reduce yields of the major cereal crop species in a period where demand is rapidly rising due to a growing global population. This requires exhaustive research to develop genetic resources in order to address the expected production deficiencies which will largely be driven by abiotic stress. Modification of multiple genes is an approach that can address the predicted challenges; however, it is time-consuming and costly to modify multiple genes simultaneously. Transcription factors represent a group of proteins regulating multiple genes simultaneously and are therefore promising targets to concurrently improve multiple traits concurrently, such as abiotic stress tolerance and grain size (a contributor to yield). Many studies have identified the complex role that transcription factors of multiple families have contributed toward abiotic stress tolerance or grain size, although research addressing both simultaneously is in its infancy despite its potential significance for cereal crop improvement. Here we discuss the potential role that transcription factors may contribute toward improving cereal crop productivity under adverse environmental conditions and offer research objectives that need to be addressed before the modification of transcription factors becomes routinely used to positively manipulate multiple target traits.

Keywords: transcription factor, abiotic stress, grain size, rice, wheat

\section{INTRODUCTION}

Rice, maize, and wheat collectively represent the primary food source for over half of the world's population and are thus crucially important for global food security. However, with increased demand from a growing global population and an increasing fluctuation in crop productivity driven by climatic variability, food security is becoming increasingly vulnerable. Modest increases of $1^{\circ} \mathrm{C}$ in average growing season temperature for instance has been predicted to reduce global wheat yields anywhere between 4 and 8\%, less for rice but greater yield losses are expected for maize, barley, and sorghum (Challinor et al., 2014; Liu B. et al., 2016; Zhao C. et al., 2017; Abhinandan et al., 2018). Already average temperature increases between 1981 and 2002 of $\sim 0.4^{\circ} \mathrm{C}$ have resulted in estimated combined annual yield losses of $42 \mathrm{Mt}$ for wheat, barley, and maize (Lobell and Field, 2007). 
Alternatively, the frequency of drought is projected to intensify, and $20 \%$ of global agricultural land is affected by salinity stress that is expected to double by 2050 both of which are considered to be the two primary threats to future agriculture (Lesk et al., 2016; Majeed et al., 2019; Nutan et al., 2019b). Our ability to ensure food security in the face of these threats therefore lies in our ability to improve cereal yields which in turn are reflections of two major and genetically manipulable morphological components: (1) number of grains $/ \mathrm{m}^{2}$ and, (2) individual grain weight (Xing and Zhang, 2010; Kennedy et al., 2016; Li et al., 2018; Ji et al., 2019). Individual grain weight is a reflection of grain size which is the culmination of complex biological processes and pathways controlled by polygenes acting preand post-anthesis to determine the maximal grain size that can be achieved (Ji et al., 2019). Addressing food security could therefore focus on increasing and/or maintaining grain size under adverse environmental conditions as a strategy to improve cereal yields.

\section{BASIC CHARACTERISTICS INFLUENCING GRAIN SIZE}

In general, grain size is co-ordinately controlled by cell expansion and proliferation in the developing endosperm and floral tissues (lemma, palea) surrounding the developing grain, determining the 'sink' capacity of the grain (Li et al., 2018). In cereals, cell proliferation precedes cell expansion to some extent, beginning at fertilization and ceasing 15-25 days later (Evers and Millar, 2002; Farooq et al., 2014; Li et al., 2018; Bian, 2019). This period of grain development predetermines the maximum size of the grain along the longitudinal and transverse axes and is quite sensitive to abiotic stress; for example in wheat, drought decreases endosperm cell proliferation reducing this 'sink' capacity (Setter and Flannigan, 2001). Alternatively, cell expansion relates to the accumulation of dry matter (protein, carbohydrates, and lipids) in the developing grain which is related to photo-assimilate production and transport. This accumulation of dry matter is the major contributor to final grain size and weight and is reported to begin 5-7 days after fertilization and ceases at physiological maturity (Coventry et al., 2003; Sreenivasulu et al., 2004). Adverse conditions during cell expansion primarily damages and/or reduces the photosynthetic area reducing the production and translocation of photoassimilates to developing grains. Optimization of source-sink pathways therefore represents a promising avenue towards contributing to grain size and weight improvement under both optimal and adverse environmental conditions.

\section{GENETIC CONTROL OF GRAIN SIZE}

In rice, maize, wheat, and barley thousands of quantitative trait loci (QTL) influencing grain size have collectively been detected, yet only a small fraction of underlying candidate genes have been functionally annotated using advanced molecular approaches such as gene cloning with the majority of studies in rice (Ayoub et al., 2002; Huang et al., 2013; Walker et al., 2013; Chen et al., 2016; Yu et al., 2017; Azizi et al., 2019; Li et al., 2019; Wang Q. et al., 2019; Watt et al., 2019). Broadly, the regulatory pathways involved in grain size regulation are represented by: hormone signaling, IKU pathway, G-protein signaling, ubiquitinproteasome pathway, the mitogen-activated protein kinase pathway and transcription factors (Li and Li, 2016; Azizi et al., 2019). Genes underlying these pathways can be negative or positive regulators of grain size as a result of allele specific epistatic interactions which can substantially influence their effect; for example OsGLA1 confers a positive effect on grain length and weight driven by a single SNP (Wang T. et al., 2019). Alternatively, $T a D A 1$ in wheat, a ubiquitin receptor negatively regulates grain size and weight by restricting cell proliferation in the maternal integuments via the ubiquitin-proteasome pathway (Liu et al., 2020).

Due to culinary preferences for different sized rice, the majority of grain size research has targeted this staple food crop, particularly the genetic engineering and functional analysis style research. Li et al. (2018) and Azizi et al. (2019) synthesize our current understanding of the pathways and genes involved in grain size regulation in rice which, due to the conservation of gene order and function between the major cereal crop species, is likely to reflect a similar genetic control of grain size in maize, wheat, and barley (Li et al., 2010; Richards et al., 2016). Despite our general understanding of the genetic control of grain size, it is the role of stress inducible transcription factors and their induction that offer promising alternative strategies to maintain and improve grain size and yield under adverse conditions primarily through their stimulation of numerous stress responsive genes (Nakashima et al., 2007; Nutan et al., 2019b).

\section{ROLE TRANSCRIPTION FACTORS PLAY IN ABIOTIC STRESS TOLERANCE}

The ability of a plant to perceive stressful conditions and subsequently respond by inducing stress responsive genes is triggered partly by transcription factors and their interaction with cis-acting promoter elements of genes in complex regulatory networks (Gujjar et al., 2014; Rahman et al., 2019). Transcriptional analyses have identified thousands of differentially expressed genes resulting from single and combined abiotic stresses indicating the complexity of stress response and gene expression regulation (Li et al., 2017; Xiong et al., 2017; Osthoff et al., 2019; Pradhan et al., 2019). Multiple transcription factor families have been implicated in abiotic stress response namely the: DREB (dehydration-responsive element binding), $\mathrm{ABRE} / \mathrm{ABF}$ (ABA-responsive element), MYB (myeloblastosis), NAC, bZIP (basic leucine zipper), and WRKY gene families (Ambawat et al., 2013; Nuruzzaman et al., 2013; Gujjar et al., 2014; Rahman et al., 2019). Often a single transcription factor is able to induce gene expression in response to multiple abiotic stress conditions. The wheat TaNAC2-5A transcription factor, for example, is induced 
by drought, salt, cold, and abscisic acid (ABA) treatment. Overexpression of TaNAC2-5A in Arabidopsis simultaneously improved drought, salinity, and freezing tolerance (Mao et al., 2012). Interestingly, stress induced TaNAC2-5A activity enhanced the expression of $D R E B 2 A$ and $A B I 5$ transcription factors. It has been shown that stress-induced and constitutive overexpression of $D R E B 2 A$ in wheat and barley improved tolerance to drought and cold stress due to increased expression of late embryogenesis abundant (LEA) genes encoding dehydrins and cold-responsive proteins that contribute to membrane stability as well as other DREB family genes, further indicating the complexity of stress response and regulatory control (Morran et al., 2011). Similarly, $\mathrm{ZmSNAC1}$ was found to improve stress tolerance through reduced dehydration, possibly through the NAC-DREB-LEA regulatory module as evidenced in wheat, barley, Arabidopsis, and rice (Lu et al., 2012; Hong et al., 2016).

\section{ROLE TRANSCRIPTION FACTORS PLAY IN GRAIN SIZE VARIATION}

Aside from the well understood role transcription factors play in plant recognition and response to abiotic stress, numerous studies across the major cereal crop species, particularly rice, have dissected their involvement in grain size modulation (Table 1). They co-ordinate cell proliferation and expansion processes not only in the developing grain itself but also in the surrounding floral tissues, lemma, and palea which additionally limit grain size. The antagonistic behavior of two bHLH-type transcription factors
(PGL1 and $A P G$ ) for example, regulates cell elongation in the lemma/palea of rice by the heterodimerization of the two encoded proteins, regulating grain length (Heang and Sassa, 2012). A major gene designated WIDE AND THICK GRAIN 1 (WTG1) in rice encodes an otubain-like protease involved in the ubiquitinproteasome pathway regulating grain size via cell expansion that is reportedly regulated by the transcription factors $A B F 1$ and $A B I 5$ (Huang et al., 2017; Li et al., 2018; Zhang et al., 2018). An ortholog in wheat $(\mathrm{TaWTG1-7B})$ is highly correlated with the expression of $A B F 2$ of the ABRE transcription factor family (Zhang et al., 2018).

The NAC transcription factor family is one of the largest, and numerous NAC genes have been implicated in the control of grain size via multiple pathways driven by the diversity of subdomains and their variable protein-protein interactions and DNAbinding activities (Olsen et al., 2005; Dwivedi et al., 2019). The OsMED15A-OsNAC024/025 regulatory module for example, positively regulates GW2, GW5 (negative regulators of grain width) and D11 (positive regulator of grain length) in rice through the interaction of the mediator tail subunit of OsMAD15A with the two NAC transcription factors that promote the recruitment of additional transcriptional machinery to the promoters of OsNAC024/025 targets (Figure 1) (Dwivedi et al., 2019). In barley,

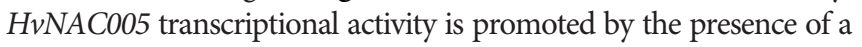
conserved C-terminal motif reportedly involved in protein-protein interaction suggesting the importance of these types of interactions for the assembly of basic transcriptional apparatus (Christiansen et al., 2016). A signal mediating protein phosphatase $2 \mathrm{C}$ (PP2C) is reported to interact with AtNAP, a homolog of $H v N A C 005$; thus $P P 2 C$ represents a possible mediator initiating transcription of HvNAC005 targets. Alternatively, the PP2C-SnRK2 ABA-

TABLE 1 | List of some key transcription factors involved directly in grain size regulation.

\begin{tabular}{|c|c|c|c|}
\hline & Locus/gene identity & Transcript factor family \& function & Reference \\
\hline \multirow[t]{4}{*}{ Barley } & HVNAC005 & NAC. Nutrient remobilization and senescence regulation & Christiansen et al., 2016 \\
\hline & HvOsbHLH107 & bHLH. Regulates cell proliferation in the longitudinal direction, homologous to OsbHLH107 & Yang et al., 2018 \\
\hline & HORVU2Hr1G089310 & MYB. Orthologous to OsGL4 which regulates cell elongation in lemma and palea & $\begin{array}{l}\text { Wu et al., 2017; Watt et al., } \\
2020\end{array}$ \\
\hline & Vrs1 & $\begin{array}{l}\text { HD-Zip. Cell proliferation in the developing lemma/palea contributes to grain length and width } \\
\text { variation }\end{array}$ & Sakuma et al., 2017 \\
\hline Maize & $Z m B Z R 1$ & BZR. Regulated cell expansion (transverse \& longitudinal) via cell size genes & Zhang et al., 2020 \\
\hline \multirow[t]{8}{*}{ Rice } & OsNF-YC10 & NF-Y. Regulates cell proliferation via cell-cycle genes and possibly OsGL7 and OsGW8 & Jia et al., 2019 \\
\hline & OsSPL16 (OsGW8) & $\begin{array}{l}\text { SBP. Regulates cell proliferation in the longitudinal and transverse direction by interaction with } \\
\text { OsGW7 }\end{array}$ & $\begin{array}{l}\text { Wang et al., 2015; Liu Q. et al. } \\
\text { (2016) }\end{array}$ \\
\hline & OsSPL13 (GLW7) & $\begin{array}{l}\text { SBP. Regulates cell elongation in lemma, interacts with OsSRS5 modifying microtubule formation, } \\
\text { grain length variation }\end{array}$ & Liu Q. et al. (2016) \\
\hline & OsGRAS19 & GRAS. Regulates brassinosteroid pathway and other regulatory genes (i.e. OsGW8, OsGW7, OsGL2) & $\begin{array}{l}\text { Chen et al., 2013; Lin et al., } \\
2019\end{array}$ \\
\hline & OsNAC024 & $\begin{array}{l}\text { NAC. Positive regulator of GW2, GW5, and D11. Interacts with OSMED15A to initiate transcription of } \\
\text { above genes }\end{array}$ & Dwivedi et al., 2019 \\
\hline & OsGRF4 & GRF. Regulates brassinosteroid pathway promoting cell expansion, small influence on proliferation & $\begin{array}{l}\text { Che et al., 2015; Hu et al., } \\
2015\end{array}$ \\
\hline & Os170 (PGL2) & $\begin{array}{l}\text { bHLH. Regulates longitudinal cell expansion in lemma/palea by forming heterodimer with APG } \\
\text { suppressing activity }\end{array}$ & Heang and Sassa, 2012 \\
\hline & OsNF-YC10 & $\begin{array}{l}\text { NF-Y. Regulates grain width via cell division and expansion in the lemma/palea through regulation of } \\
\text { cell cycle genes primarily }\end{array}$ & Jia et al., 2019 \\
\hline \multirow[t]{3}{*}{ Wheat } & TaNAM-B1 & NAC. Nutrient remobilization and senescence regulation & Uauy et al., 2006 \\
\hline & TaGLW7 & SBP. Orthologous to rice OSSPL13 regulating grain length & Yang et al., 2019 \\
\hline & TaABF2 & $\begin{array}{l}\text { ABRE/ABF. Regulates TaWTG1-7B to antagonistically manipulate cell proliferation and expansion. } \\
\text { Orthologous to OsWTG1 }\end{array}$ & $\begin{array}{l}\text { Huang et al., 2017; Zhang } \\
\text { et al., } 2018\end{array}$ \\
\hline
\end{tabular}




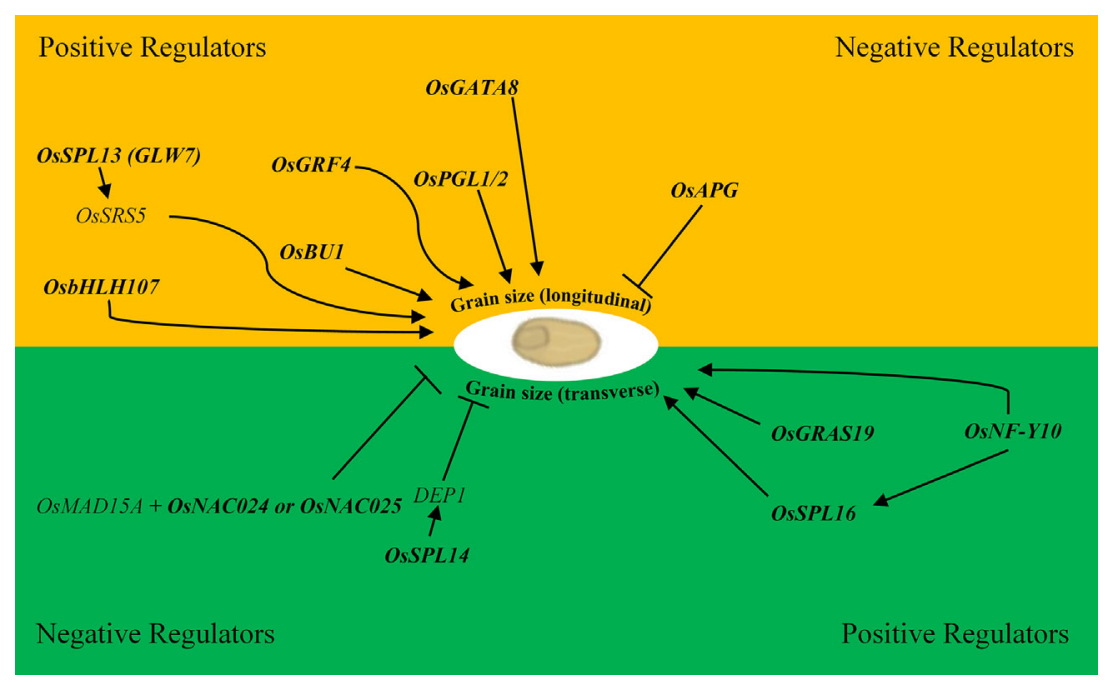

FIGURE 1 | Positive and negative regulatory transcription factors of rice involved in grain size variation in the longitudinal (length; yellow) and transverse directions (width and thickness; green). Bold text represents transcription factors. Arrows represent a positive interaction, and blunt ends are negative interactions i.e. OsSPL16 positively regulates $D E P 1$ which in-turn negatively regulates grain width.

responsive complex is reported to enhance bZIP transcription factor activity in Arabidopsis suggesting that this same signaling pathway is active in barley (Hirayama and Umezawa, 2010; Zhang and Gan, 2012).

\section{APPLICATION OF TRANSCRIPTION FACTORS TO MANIPULATE GRAIN SIZE UNDER STRESSFUL CONDITIONS}

Despite the diversity of transcription factors, their function, and their involvement in abiotic stress response and regulation of grain size, research marrying the two is surprisingly limited considering the contribution this knowledge could provide to improving cereal productivity. Overexpression of NACs for example, have significantly improved tolerance to drought, salinity, and cold stress in rice and maize (Nuruzzaman et al., 2013). OsNAC022 overexpression in rice was shown to significantly improve drought and salinity tolerance, although there was a significant negative effect on 1,000-grain weight, a reflection of grain size indicating the importance of identifying suitable transcription factors that can simultaneously improve both stress tolerance and grain size if transcription factors were going to be manipulated for trait improvement (Hong et al., 2016). This study however, drove overexpression via the constitutive maize ubiquitin promoter, an approach known to often confer undesirable phenotypes under optimal environmental conditions as was the case for constitutive overexpression of Ubi1:OsNAC6. It is possible that maintenance of 1,000 -grain weight in this instance could have been achieved through the use of a stress inducible and/or tissue specific promoter coupled to OcNACO22 such as rice Wsil8 gene promoter which exhibits strong stress induced expression and elevated activity in developing grains specifically (Nakashima et al., 2007; Yi et al., 2011). A GATA-transcription factor, OsGATA 8 has successfully been manipulated, and constitutive expression has been proven to improve drought and salinity tolerance while simultaneously increasing grain length and TGW with no undesirable phenotypes in rice and Arabidopsis transgenic lines (Nutan et al., 2019b). It was shown that OsGATA8 regulated genes involved in reactive-oxygen scavenging enzymes, chlorophyllbiosynthesis enzymes as well as other transcription factors such as OsDREB1A.

A WRKY transcription factor OsWRKY78 positively regulated grain width and was upregulated by $\mathrm{ABA}$ and salinity, but downregulated by cold (Zhang et al., 2011). OsSPL14 positively regulates DEP1 (Figure 1) in-turn influencing grain size, plant architecture, and yield (Jiao et al., 2010; Zhou and Luo, 2013; Stief et al., 2014; Zheng and Qu, 2015; Yue et al., 2017; Watt et al., 2019). Promisingly, OsSPL14 was recently shown to regulate OsTB1 which acted as a negative regulator of OsWRKY94 and suppressed the cold stress induced expression of OsMADS57 indicating the potential to manipulate OSSPL14 to simultaneously improve abiotic stress tolerance and grain size (Chen et al., 2018; Nutan et al., 2019a). The R2R3-subclass of the MYB transcription factor family is primarily involved in developmental processes and abiotic stress response compared to the other three subclasses suggesting there is potential to improve both characteristics by focusing on the manipulation of this subclass specifically (Ambawat et al., 2013; Hou et al., 2018). OsGAMYB for example, an R2R3MYB transcription factor involved in gibberellic acid signalling, has been linked to both grain size variation and response to salinity stress possibly through miR159 induction in separate studies (Zhao Y. et al., 2017; Liu et al., 2019). This suggests that it may be possible 
to manipulate stress response and grain size co-ordinately by targeting transcription factors and/or components of the regulatory network such as microRNAs, the main targets of which are transcription factors (Zhou and Luo, 2013).

\section{CONCLUSIONS AND FUTURE PERSPECTIVES}

The relationship between grain size, yield and the negative effect abiotic stress has on these traits requires further research in order to address the expected threats associated with climate change. The complex regulatory pathways involved in grain size and abiotic stress response suggest that modification of a single transcription factor may offer potential strategies to improving grain size, yield, and abiotic stress tolerance simultaneously as observed by Nutan et al. (2019b). Research needs to address the combined effect of stress response and grain size to transcription factor manipulation to identify on a species-specific level, suitable candidates for trait improvement, something that can currently only be conferred based on a limited number of studies. As between Arabidopsis and tomato (Zhou and Luo, 2013), microRNAs which in-turn regulate transcription factors can confer either negative or positive effects on trait expression depending on the species background; in cereals this would necessitate further research, but the relative conservation of gene order and function between the major cereal crop species may enable rapid transferability of knowledge from one cereal species to another. However, care must be taken if a transcription factor is to be manipulated through microRNA modification due to the large gene networks these microRNAs target; miR156 for example, regulates a reported 11 OsSPL genes including OsSPL14

\section{REFERENCES}

Abhinandan, K., Skori, L., Stanic, M., Hickerson, N. M. N., Jamshed, M., and Samuel, M. A. (2018). Abiotic stress signaling in wheat - An inclusive overview of hormonal interactions during abiotic stress responses in wheat. Front. Plant Sci. 9, 1-25. doi: 10.3389/fpls.2018.00734

Ambawat, S., Sharma, P., Yadav, N. R., and Yadav, R. C. (2013). MYB transcription factor genes as regulators for plant responses: an overview. Physiol. Mol. Biol. Plants 19, 307-321. doi: 10.1007/s12298-013-0179-1

Ayoub, M., Symons, S. S., Edney, M. M., and Mather, D. D. (2002). QTLs affecting kernel size and shape in a two-rowed by six-rowed barley cross. Theor. Appl. Genet. 105, 237-247. doi: 10.1007/s00122-002-0941-1

Azizi, P., Osman, M., Hanafi, M. M., Sahebi, M., Rafii, M. Y., Taheri, S., et al. (2019). Molecular insights into the regulation of rice kernel elongation. Crit. Rev. Biotechnol. 39, 904-923. doi: 10.1080/07388551.2019.1632257

Bian, J. (2019). Transcriptional dynamics of grain development in barley (Hordeum vulgare L.). Int. J. Mol. Sci. 20, 962-978. doi: 10.3390/ijms20040962

Challinor, A. J., Watson, J., Lobell, D. B., Howden, S. M., Smith, D. R., and Chhetri, N. (2014). A meta-analysis of crop yield under climate change and adaptation. Nat. Clim. Change 4, 287-291. doi: 10.1038/nclimate2153

Che, R., Tong, H., Shi, B., Liu, Y., Fang, S., Liu, D., et al. (2015). Control of grain size and rice yield by GL2-mediated brassinosteroid responses. Nat. Plants 2, 1-7. doi: 10.1038/nplants.2015.1195

Chen, L., Xiong, G., Cui, X., Yan, M., Xu, T., Qian, Q., et al. (2013). OsGRAS19 may be a novel component involved in the brassinosteroid signaling pathway in rice. Mol. Plant 6, 988-991. doi: 10.1093/mp/sst027 thus the manipulation of miR156 may confer a positive or negative phenotypic response depending on the SPL gene target and necessitates a greater level of understanding (Xie et al., 2006; Wang and Wang, 2015). In addition to alternative targets of transcription factor networks i.e. microRNAs, constitutive overexpression of transcription factors as a tool for trait improvement has been proven to induce negative pleiotropic effects on phenotypes in many instances, thus research should address trait response using stress induced and/or tissue specific promoters to improve commercial viability of certain transcription factor modifications.

\section{AUTHOR CONTRIBUTIONS}

CW came up with the initial concept and wrote the initial draft in conjunction with GZ and CL. All authors contributed to the article and approved the submitted version.

\section{FUNDING}

CW receives a postgraduate scholarship from the Grains Research and Development Corporation (GRDC), project code UMU1903-003RSX.

\section{ACKNOWLEDGMENTS}

The corresponding author CW would like to thank all co-authors for their guidance. Additionally, all authors would like to thank the GRDC for funding.

Chen, J., Zhang, L., Liu, S., Li, Z., Huang, R., Li, Y., et al. (2016). The genetic basis of natural variation in kernel size and related traits using a four-way cross population in maize. PLoS One 11, 1-12. doi: 10.1371/journal.pone.0153428

Chen, L., Zhao, Y., Xu, S., Zhang, Z., Xu, Y., Zhang, J., et al. (2018). OsMADS57 together with OsTB1 coordinates transcription of its target OsWRKY94 and D14 to switch its organogenesis to defense for cold adaptation in rice. New Phytol. 218, 219-231. doi: 10.1111/nph.14977

Christiansen, M. W., Matthewman, C., Podzimska-Sroka, D., O’Shea, C., Lindemose, S., Møllegaard, N. E., et al. (2016). Barley plants over-expressing the NAC transcription factor gene HvNACO05 show stunting and delay in development combined with early senescence. J. Exp. Bot. 67, 5259-5273. doi: 10.1093/jxb/erw286

Coventry, S. J., Barr, A. R., Eglinton, J. K., and McDonald, G. K. (2003). The determinants and genome locations influencing grain weight and size in barley. Aust. J. Agric. Res. 54, 1103-1115. doi: 10.1071/AR02194

Dwivedi, N., Maji, S., Waseem, M., Thakur, P., Kumar, V., Parida, S. K., et al. (2019). The Mediator subunit OsMED15a is a transcriptional co-regulator of seed size/weight-modulating genes in rice. Biochim. Biophys. Acta 1862, 1-17. doi: 10.1016/j.bbagrm.2019.194432

Evers, T., and Millar, S. (2002). Cereal grain structure and development: Some implications for quality. J. Cereal Sci. 36, 261-284. doi: 10.1006/jcrs.2002.0435

Farooq, M., Wahid, A., and Siddique, K. (2014). "Physiology of grain development in cereals," in Handbook of Plant and Crop Physiology, 3rd ed. Ed. M. Pessarakli (Boca Raton, FL: Taylor and Francis Group), 301-308.

Gujjar, R. S., Akhtar, M., and Singh, M. (2014). Transcription factors in abiotic stress tolerance. Indian J. Plant Physiol. 19, 306-316. doi: 10.1007/s40502-0140121-8 
Heang, D., and Sassa, H. (2012). An atypical bHLH protein encoded by POSITIVE REGULATOR OF GRAIN LENGTH 2 is involved in controlling grain length and weight of rice through interaction with a typical bHLH protein APG. Breed. Sci. 62, 133-141. doi: 10.1270/jsbbs.62.133

Hirayama, T., and Umezawa, T. (2010). The PP2C-SnRK2 complex: the central regulator of an abscisic acid signaling pathway. Plant Signal. Behav. 5, 160-163. doi: $10.4161 /$ psb.5.2.10460

Hong, Y., Zhang, H., Huang, L., Li, D., and Song, F. (2016). Overexpression of a stress-responsive nac transcription factor gene ONAC022 improves drought and salt tolerance in rice. Front. Plant Sci. 7, 1-19. doi: 10.3389/fpls.2016.00004

Hou, D., Cheng, Z., Xie, L., Li, X., Li, J., Mu, S., et al. (2018). The R2R3MYB Gene Family in Phyllostachys edulis: Genome-Wide Analysis and Identification of Stress or Development-Related R2R3MYBs. Front. Plant Sci. 9, 1-22. doi: 10.3389/fpls.2018.00738

Hu, J., Wang, Y., Fang, Y., Zeng, L., Xu, J., Yu, H., et al. (2015). A rare allele of GS2 enhances grain size and grain yield in rice. Mol. Plant 8, 1455-1465. doi: 10.1016/j.molp.2015.07.002

Huang, R., Jiang, L., Zheng, J., Wang, T., Wang, H., Huang, Y., et al. (2013). Genetic bases of rice grain shape: so many genes, so little known. Trends Plant Sci. 18, 218-226. doi: 10.1016/j.tplants.2012.11.001

Huang, K., Wang, D., Duan, P., Zhang, B., Xu, R., Li, N., et al. (2017). WIDE AND THICK GRAIN 1, which encodes an otubain-like protease with deubiquitination activity, influences grain size and shape in rice. Plant J. 91, 849-860. doi: 10.1111/tpj.13613

Ji, X., Du, Y., Li, F., Sun, H., Zhang, J., Li, J., et al. (2019). The basic helix-loop-helix transcription factor, OsPIL15, regulates grain size via directly targeting a purine permease gene OsPUP7 in rice. Plant Biotechnol. J. 17, 1527-1537. doi: $10.1111 /$ pbi.13075

Jia, S., Xiong, Y., Xiao, P., Wang, X., and Yao, J. (2019). OsNF-YC10, a seed preferentially expressed gene regulates grain width by affecting cell proliferation in rice. Plant Sci. 280, 219-227. doi: 10.1016/j.plantsci.2018.09.021

Jiao, Y., Wang, Y., Xue, D., Wang, J., Yan, M., Liu, G., et al. (2010). Regulation of OsSPL14 by OsmiR156 defines ideal plant architecture in rice. Nat. Genet. 42, 541-544. doi: 10.1038/ng.591

Kennedy, S. P., Bingham, I. J., and Spink, J. H. (2016). Determinants of spring barley yield in a high-yield potential environment. J. Agric. Sci. 155, 60-80. doi: $10.1017 /$ S0021859616000289

Lesk, C., Rowhani, P., and Ramankutty, N. (2016). Influence of extreme weather disasters on global crop production. Nature 529, 84-87. doi: 10.1038/nature16467

Li, N., and Li, Y. (2016). Signaling pathways of seed size control in plants. Curr. Opin. Plant Biol. 33, 23-32. doi: 10.1016/j.pbi.2016.05.008

Li, Q., Li, L., Yang, X., Warburton, M. L., Bai, G., Dai, J., et al. (2010). Relationship, evolutionary fate and function of two maize co-orthologs of rice GW2 associated with kernel size and weight. BMC Plant Biol. 10, 143-158. doi: 10.1186/1471-2229-10-143

Li, P., Cao, W., Fang, H., Xu, S., Yin, S., Zhang, Y., et al. (2017). Transcriptomic profiling of the maize (Zea mays L.) leaf response to abiotic stresses at the seedling stage. Front. Plant Sci. 8, 1-13. doi: 10.3389/fpls.2017.00290

Li, N., Xu, R., Duan, P., and Li, Y. (2018). Control of grain size in rice. Plant Reprod. 31, 1-15. doi: 10.1007/s00497-018-0333-6

Li, L., Li, X., Li, L., Schnable, J., Gu, R., and Wang, J. (2019). QTL identification and epistatic effect analysis of seed size- and weight-related traits in Zea mays L. Mol. Breed. 39, 1-11. doi: 10.1007/s11032-019-0981-8

Lin, Z., Yan, J., Su, J., Liu, H., Hu, C., Li, G., et al. (2019). Novel OsGRAS19 mutant, D26, positively regulates grain shape in rice (Oryza sativa). Funct. Plant Biol. 46, 857-868. doi: 10.1071/FP18266

Liu, B., Asseng, S., Müller, C., Ewert, F., Elliott, J., Lobell, David, B., et al. (2016). Similar estimates of temperature impacts on global wheat yield by three independent methods. Nat. Clim. Change 6, 1130-1136. doi: 10.1038/ nclimate3115

Liu, Q., Harberd, Nicholas, P., and Fu, X. (2016). SQUAMOSA promoter binding protein-like transcription factors: Targets for improving cereal grain yield. Mol. Plant 9, 765-767. doi: 10.1016/j.molp.2016.04.008

Liu, C., Chen, K., Zhao, X., Wang, X., Shen, C., Zhu, Y., et al. (2019). Identification of genes for salt tolerance and yield-related traits in rice plants grown hydroponically and under saline field conditions by genome-wide association study. Rice 12, 88. doi: 10.1186/s12284-019-0349-z
Liu, H., Li, H., Hao, C., Wang, K., Wang, Y., Qin, L., et al. (2020). TaDA1, a conserved negative regulator of kernel size, has an additive effect with TaGW2 in common wheat (Triticum aestivum L.). Plant Biotechnol. J. 18, 1330-1342. doi: 10.1111/pbi.13298

Lobell, D. B., and Field, C. B. (2007). Global scale climate-crop yield relationships and the impacts of recent warming. Environ. Res. Lett. 2, 1-17. doi: 10.1088/ 1748-9326/1082/1081/014002

Lu, M., Ying, S., Zhang, D.-F., Shi, Y.-S., Song, Y.-C., Wang, T.-Y., et al. (2012). A maize stress-responsive NAC transcription factor, ZmSNAC1, confers enhanced tolerance to dehydration in transgenic Arabidopsis. Plant Cell Rep. 31, 1701-1711. doi: 10.1007/s00299-012-1284-2

Majeed, A., Muhammad, Z., Islam, S., and Ahmad, H. (2019). Salinity imposed stress on principal cereal crops and employing seed priming as a sustainable management approach. Acta Ecol. Sin. 39, 280-283. doi: 10.1016/ j.chnaes.2018.09.004

Mao, X., Zhang, H., Qian, X., Li, A., Zhao, G., and Jing, R. (2012). TaNAC2, a NAC-type wheat transcription factor conferring enhanced multiple abiotic stress tolerances in Arabidopsis. J. Exp. Bot. 63, 2933-2946. doi: 10.1093/jxb/ err462

Morran, S., Eini, O., Pyvovarenko, T., Parent, B., Singh, R., Ismagul, A., et al. (2011). Improvement of stress tolerance of wheat and barley by modulation of expression of DREB/CBF factors. Plant Biotechnol. J. 9, 230-249. doi: 10.1111/ j.1467-7652.2010.00547.x

Nakashima, K., Tran, L.-S. P., Van Nguyen, D., Fujita, M., Maruyama, K., Todaka, D., et al. (2007). Functional analysis of a NAC-type transcription factor OsNAC6 involved in abiotic and biotic stress-responsive gene expression in rice. Plant J. 51, 617-630. doi: 10.1111/j.1365-313X.2007.03168.x

Nuruzzaman, M., Sharoni, A. M., and Kikuchi, S. (2013). Roles of NAC transcription factors in the regulation of biotic and abiotic stress responses in plants. Front. Microbiol. 4, 248-248. doi: 10.3389/fmicb.2013.00248

Nutan, K. K., Rathore, R. S., Tripathi, A. K., Mishra, M., Pareek, A., and SinglaPareek, S. L. (2019a). Integrating the dynamics of yield traits in rice in response to environmental changes. J. Exp. Bot. 71, 490-506. doi: 10.1093/jxb/erz364

Nutan, K. K., Singla-Pareek, S. L., and Pareek, A. (2019b). The Saltol QTLlocalized transcription factor OsGATA8 plays an important role in stress tolerance and seed development in Arabidopsis and rice. J. Exp. Bot. 71, 684-698. doi: 10.1093/jxb/erz368

Olsen, A. N., Ernst, H. A., Leggio, L. L., and Skriver, K. (2005). NAC transcription factors: structurally distinct, functionally diverse. Trends Plant Sci. 10, 79-87. doi: $10.1016 /$ j.tplants.2004.12.010

Osthoff, A., Donà dalle Rose, P., Baldauf, J. A., Piepho, H.-P., and Hochholdinger, F. (2019). Transcriptomic reprogramming of barley seminal roots by combined water deficit and salt stress. BMC Genomics 20, 325-339. doi: 10.1186/s12864019-5634-0

Pradhan, S. K., Pandit, E., Nayak, D. K., Behera, L., and Mohapatra, T. (2019). Genes, pathways and transcription factors involved in seedling stage chilling stress tolerance in indica rice through RNA-Seq analysis. BMC Plant Biol. 19, 352-369. doi: 10.1186/s12870-12019-11922-12878

Rahman, M.U., Munazza, I., Shanzay, Q., Shazia Anwer, B., and Kausar, M. (2019). "Chapter 27 - Abiotic stress signaling in rice crop," in Advances in Rice Research for Abiotic Stress Tolerance. Eds. M. Hasanuzzaman, M. Fujita, K. Nahar and J. K. Biswas (Cambridge, UK: Woodhead Publishing), 551-569.

Richards, J., Chao, S., Friesen, T., and Brueggeman, R. (2016). Fine mapping of the barley chromosome $6 \mathrm{H}$ net form net blotch susceptibility locus. G3: Genes Genomes Genet. 6, 1809-1818. doi: 10.1534/g3.116.028902

Sakuma, S., Lundqvist, U., Kakei, Y., Thirulogachandar, V., Suzuki, T., Hori, K., et al. (2017). Extreme suppression of lateral floret development by a single amino acid change in the VRS1 transcription factor. Plant Physiol. 175, 17201731. doi: $10.1104 /$ pp. 17.01149

Setter, T. L., and Flannigan, B. A. (2001). Water deficit inhibits cell division and expression of transcripts involved in cell proliferation and endoreduplication in maize endosperm. J. Exp. Bot. 52, 1401-1408. doi: 10.1093/jexbot/ 52.360 .1401

Sreenivasulu, N., Altschmied, L., Radchuk, V., Gubatz, S., Wobus, U., and Weschke, W. (2004). Transcript profiles and deduced changes of metabolic pathways in maternal and filial tissues of developing barley grains. Plant J. 37, 539-553. doi: 10.1046/j.1365-313X.2003.01981.x 
Stief, A., Altmann, S., Hoffmann, K., Pant, B. D., Scheible, W.-R., and Bäurle, I. (2014). Arabidopsis miR156 regulates tolerance to recurring environmental stress through SPL transcription factors. Plant Cell. 26, 1792-1807. doi: 10.1105/tpc.114.123851

Uauy, C., Brevis, J. C., and Dubcovsky, J. (2006). The high grain protein content gene $G p c-B 1$ accelerates senescence and has pleiotropic effects on protein content in wheat. J. Exp. Bot. 57, 2785-2794. doi: 10.1093/jxb/erl047

Walker, C. K., Ford, R., Munoz-Amatriam, M., and Panozzo, J. F. (2013). The detection of QTLs in barley associated with endosperm hardness, grain density, grain size and malting quality using rapid phenotyping tools. Theor. Appl. Genet. 126, 2533-2551. doi: 10.1007/s00122-013-2153-2

Wang, H., and Wang, H. (2015). The miR156/SPL module, a regulatory hub and versatile toolbox, gears up crops for enhanced agronomic traits. Mol. Plant 8, 677-688. doi: 10.1016/j.molp.2015.01.008

Wang, S., Li, S., Liu, Q., Wu, K., Zhang, J., Wang, S., et al. (2015). The OsSPL16$G W 7$ regulatory module determines grain shape and simultaneously improves rice yield and grain quality. Nat. Genet. 47, 949-954. doi: 10.1038/ng.3352

Wang, Q., Sun, G., Ren, X., Du, B., Cheng, Y., Wang, Y., et al. (2019). Dissecting the genetic basis of grain size and weight in barley (Hordeum vulgare L.) by QTL and comparative genetic analyses. Front. Plant Sci. 10, 469. doi: 10.3389/ fpls.2019.00469

Wang, T., Zou, T., He, Z., Yuan, G., Luo, T., Zhu, J., et al. (2019). GRAIN LENGTH AND AWN 1 negatively regulates grain size in rice. J. Integr. Plant Biol. 61, 1036-1042. doi: 10.1111/jipb.12736

Watt, C., Zhou, G., McFawn, L.-A., Chalmers, K. J., and Li, C. (2019). Fine mapping of $q G L 5 H$, a major grain length locus in barley (Hordeum vulgare L.). Theor. Appl. Genet. 132, 883-893. doi: 10.1007/s00122-018-3243-y

Watt, C., Zhou, G., McFawn, L.-A., and Li, C. (2020). Fine mapping qGL2H, a major locus controlling grain length in barley (Hordeum vulgare L.). Theor. Appl. Genet. 133, 2095-2103. doi: 10.1007/s00122-00020-03579-Z

Wu, W., Liu, X., Wang, M., Meyer, R. S., Luo, X., Ndjiondjop, M.-N., et al. (2017). A single-nucleotide polymorphism causes smaller grain size and loss of seed shattering during African rice domestication. Nat. Plants 3, 1-7. doi: 10.1038/ nplants.2017.1064

Xie, K., Wu, C., and Xiong, L. (2006). Genomic Organization, Differential Expression, and Interaction of SQUAMOSA Promoter-Binding-Like Transcription Factors and microRNA156 in Rice. Plant Physiol. 142, 280293. doi: 10.1104/pp.106.084475

Xing, Y., and Zhang, Q. (2010). Genetic and molecular bases of rice yield. Annu. Rev. Plant Biol. 61, 421-442. doi: 10.1146/annurev-arplant-042809-112209

Xiong, H., Guo, H., Xie, Y., Zhao, L., Gu, J., Zhao, S., et al. (2017). RNAseq analysis reveals pathways and candidate genes associated with salinity tolerance in a spaceflight-induced wheat mutant. Sci. Rep. 7, 1-13. doi: 10.1038/s4159841017-03024-41590

Yang, X., Ren, Y., Cai, Y., Niu, M., Feng, Z., Jing, R., et al. (2018). Overexpression of OsbHLH107, a member of the basic helix-loop-helix transcription factor family, enhances grain size in rice (Oryza sativa L.). Rice 11, 1-12. doi: 10.1186/ s12284-018-0237-y

Yang, C. C., Ma, J., Li, T., Luo, W., Mu, Y., Tang, H. P., et al. (2019). Structural organization and functional activity of the orthologous TaGLW7 genes in bread wheat (Triticum aestivum L.). Russ. J. Genet. 55, 571-579. doi: 10.1134/ S1022795419050168

Yi, N., Oh, S.-J., Kim, Y. S., Jang, H.-J., Park, S.-H., Jeong, J. S., et al. (2011). Analysis of the Wsi18, a stress-inducible promoter that is active in the whole grain of transgenic rice. Transgenic Res. 20, 153-163. doi: 10.1007/s11248-0109400-y

Yu, J., Xiong, H., Zhu, X., Zhang, H., Li, H., Miao, J., et al. (2017). OsLG3 contributing to rice grain length and yield was mined by Ho-LAMap. BMC Biol. 15, 28-46. doi: 10.1186/s12915-017-0365-7

Yue, E., Liu, Z., Li, C., Li, Y., Liu, Q., and Xu, J.-H. (2017). Overexpression of miR529a confers enhanced resistance to oxidative stress in rice (Oryza sativa L.). Plant Cell Rep. 36, 1171-1182. doi: 10.1007/s00299-017-2146-8

Zhang, K., and Gan, S.-S. (2012). An Abscisic Acid-AtNAP Transcription FactorSAG113 Protein Phosphatase 2C Regulatory Chain for Controlling Dehydration in Senescing Arabidopsis Leaves. Plant Physiol. 158, 961-969. doi: 10.1104/pp.111.190876

Zhang, C.-Q., Xu, Y., Lu, Y., Yu, H.-X., Gu, M.-H., and Liu, Q.-Q. (2011). The WRKY transcription factor OsWRKY78 regulates stem elongation and seed development in rice. Planta 234, 541-554. doi: 10.1007/s00425-011-1423-y

Zhang, H., Ma, J., Liu, J., Mu, Y., Tang, H., Liu, Y., et al. (2018). Molecular characterization of the TaWTG1 in bread wheat (Triticum aestivum L.). Gene 678, 23-32. doi: 10.1016/j.gene.2018.08.010

Zhang, X., Guo, W., Du, D., Pu, L., and Zhang, C. (2020). Overexpression of a maize BR transcription factor ZmBZR1 in Arabidopsis enlarges organ and seed size of the transgenic plants. Plant Sci. 292 1-10. doi: 10.1016/ j.plantsci.2019.110378

Zhao, C., Liu, B., Piao, S., Wang, X., Lobell, D. B., Huang, Y., et al. (2017). Temperature increase reduces global yields of major crops in four independent estimates. Proc. Natl. Acad. Sci. 114, 9326-9331. doi: 10.1073/ pnas.1701762114

Zhao, Y., Wen, H., Teotia, S., Du, Y., Zhang, J., Li, J., et al. (2017). Suppression of microRNA159 impacts multiple agronomic traits in rice (Oryza sativa L.). BMC Plant Biol. 17, 215. doi: 10.1186/s12870-017-1171-7

Zheng, L.-L., and Qu, L.-H. (2015). Application of microRNA gene resources in the improvement of agronomic traits in rice. Plant Biotechnol. J. 13, 329-336. doi: $10.1111 / \mathrm{pbi} .12321$

Zhou, M., and Luo, H. (2013). MicroRNA-mediated gene regulation: potential applications for plant genetic engineering. Plant Mol. Biol. 83, 59-75. doi: 10.1007/s11103-013-0089-1

Conflict of Interest: The authors declare that the research was conducted in the absence of any commercial or financial relationships that could be construed as a potential conflict of interest.

Copyright (C) 2020 Watt, Zhou and Li. This is an open-access article distributed under the terms of the Creative Commons Attribution License (CC BY). The use, distribution or reproduction in other forums is permitted, provided the original author(s) and the copyright owner(s) are credited and that the original publication in this journal is cited, in accordance with accepted academic practice. No use, distribution or reproduction is permitted which does not comply with these terms. 